\title{
DISTRIBUTION AND ABUNDANCE OF RODENTS IN FARMLANDS: A CASE STUDY IN ALLELTU WOREDA, ETHIOPIA
}

\author{
Manyingerew Shenkut, Assefa Mebrate and Balakrishnan, M. * \\ Department of Biology, Faculty of Science, Addis Ababa University, PO Box 1176 \\ Addis Ababa, Ethiopia. E-mail: balak212@ yahoo.com
}

\begin{abstract}
A study on the distribution and abundance of rodents was carried out in three live trapping grids in wheat, bean and lentil fields in Alleltu Woreda, Ethiopia. A survey was also conducted in habitats outside the cultivated fields. A total of 260 rodents were trapped from the cultivated fields during 3087 trap-nights and 61 from outside cultivated areas during 675 trap-nights. The rodents trapped were Mastomys natalensis, Mus mahomet and Arvicanthis abyssinicus. Rodent populations reached their peak when the crops were maturing, and declined after harvest. Distribution and abundance of rodents showed significant temporal variation. M. natalensis was the dominant species in the cultivated fields whereas A. abyssinicus was more outside the cultivated fields. The population density of rodents estimated by Capture - Mark - Recapture method ranged from 120/ha in the lentil field to $379 / \mathrm{ha}$ in the wheat field. The total biomass of rodents in wheat, bean and lentil grids was $5019 \mathrm{~g}, 2200 \mathrm{~g}$ and $1520 \mathrm{~g}$, respectively.
\end{abstract}

Key words/phrases: Abundance, biomass, density, distribution, rodents

\section{INTRODUCTION}

Although there are about 2000 species of rodents, only a few of them are agricultural pests. In Africa, only 77 species are reported to cause damage to agriculture (Wilson and Reeder, 1993). Most of the harmful rodents are members of the Family Muridae. Among the rodent pests of Africa, 12 species are recognized as most notorious pests in east Africa (Fiedler, 1994). Eleven of the 84 rodent species in Ethiopia are major agricultural pests. Arvicanthis spp. and Mastomys spp. are major pests of maize (Afework Bekele and Leirs, 1997). These species have wide distributions across many parts of Ethiopia (Afework Bekele et al., 1993).

Agricultural fields are homogenous landscapes because the vegetation is dominated by one or few crop species. Farmers attempt to enhance soil fertility and water availability for increased productivity. This in turn makes available food resources not only for humans, but also for pests. Many rodents are common in fields with cereal crops, which constitute the largest part of the total area used for agriculture in the world (FAO, 2002). Population dynamics of rodent pests in agriculture can show at least three different basic patterns. Populations may be relatively stable or irregularly fluctuate as in Rattus tiomanicus in oil palms
(Williams, 1985), or they may show strong seasonal fluctuations combined with inter-annual differences as in the African multimammate mouse, Mastomys natalensis in maize fields (Afework Bekele and Leirs, 1997). They may also be eruptive with irregular peak years alternated with periods of lower populations as reported in Mus domesticus in Australia (Leirs, 2003). The African multimammate mouse shows a strict breeding seasonality, closely linked to rainfall periods, probably through the stimulating effect of germinating grasses (Leirs et al., 1994). This induces maturation of sub-adult females, which would produce large number of young in a short period. Favorable conditions would lead to high populations that escape the normal densitydependent regulation leading to population eruption (Pech et al., 1999).

Rodent damage is rarely uniform in time; it follows crop phenology. Rice field rats cause more damage during some stages of growth of paddy than during other stages (Tristiani and Murakami, 1998). Multimammate mice dig up planted maize seeds, but are harmless during the growth of maize plants until the crops start ripening (Makundi et al., 1999). The wood mouse, Apodemus sylvaticus is a threat to sugar beet fields only for two weeks after sowing (Peltz, 1989). In perennial crops such as

\footnotetext{
*Author to whom correspondence should be addressed.
} 
coconut or cocoa, rodent damage is more continuous, but may vary to coincide with fruiting (Williams, 1985). Estimates of pre-harvest losses due to rodents typically fall between $5-15 \%$ in cereal production systems. In maize farms at Ziway, Ethiopia, Afework Bekele et al. (2003) have estimated rodent-related crop damage up to $26 \%$. Rodent outbreaks driven by climatic fluctuations and environmental variations are also noticed (Afework Bekele and Leirs, 1997; Douganboupha et al., 2003).

The present study aims at finding the diversity, distribution patterns, relative abundance and biomass of rodents in farmlands in Central Ethiopia, where crop damage due to rodent pests was reported.

\section{THE STUDY AREA AND METHODS}

The present investigation was carried out in a school compound belonging to the Ethiopian Children's Fund, which is located at $9^{\circ} 11^{\prime} \mathrm{N}, 39^{\circ}$

$08^{\prime}$ E, in Mikawa Peasant Association, Alleltu Woreda, Oromia Region (Fig. 1). This location is about $55 \mathrm{~km}$ northwest of Addis Ababa on the Dessie road at an altitude of around 2645 m.a.s.l. Mean annual rainfall in the study area was 1089 $\mathrm{mm}$ with a bi-modal pattern of low rainfall between March and April and high rainfall between July and September. The area has a relatively flat topography.

Major crops sown during the study period were wheat, beans and lentils. Wheat was sown in August and harvested in January, beans were sown in July and harvested in November, while lentils were sown in September and harvested in February. For the purpose of the present study, three $70 \times 70 \mathrm{~m}^{2}$ live trapping grids were established for Capture-Mark-Recapture (CMR) study, one each in wheat, bean and lentil fields. Each of the grids consisted of seven lines, $10 \mathrm{~m}$ apart, with a trap station at every $10 \mathrm{~m}$. A total of 49 Sherman traps $(7.6 \times 8.9 \times 22.9 \mathrm{~cm}$. size $)$ was set in each grid. Trapping was done for three consecutive days at intervals of two weeks from October 2002 to March 2003 in the cultivated fields. This comprised 11 trapping sessions. There were 3087 trap-nights in the farmlands.

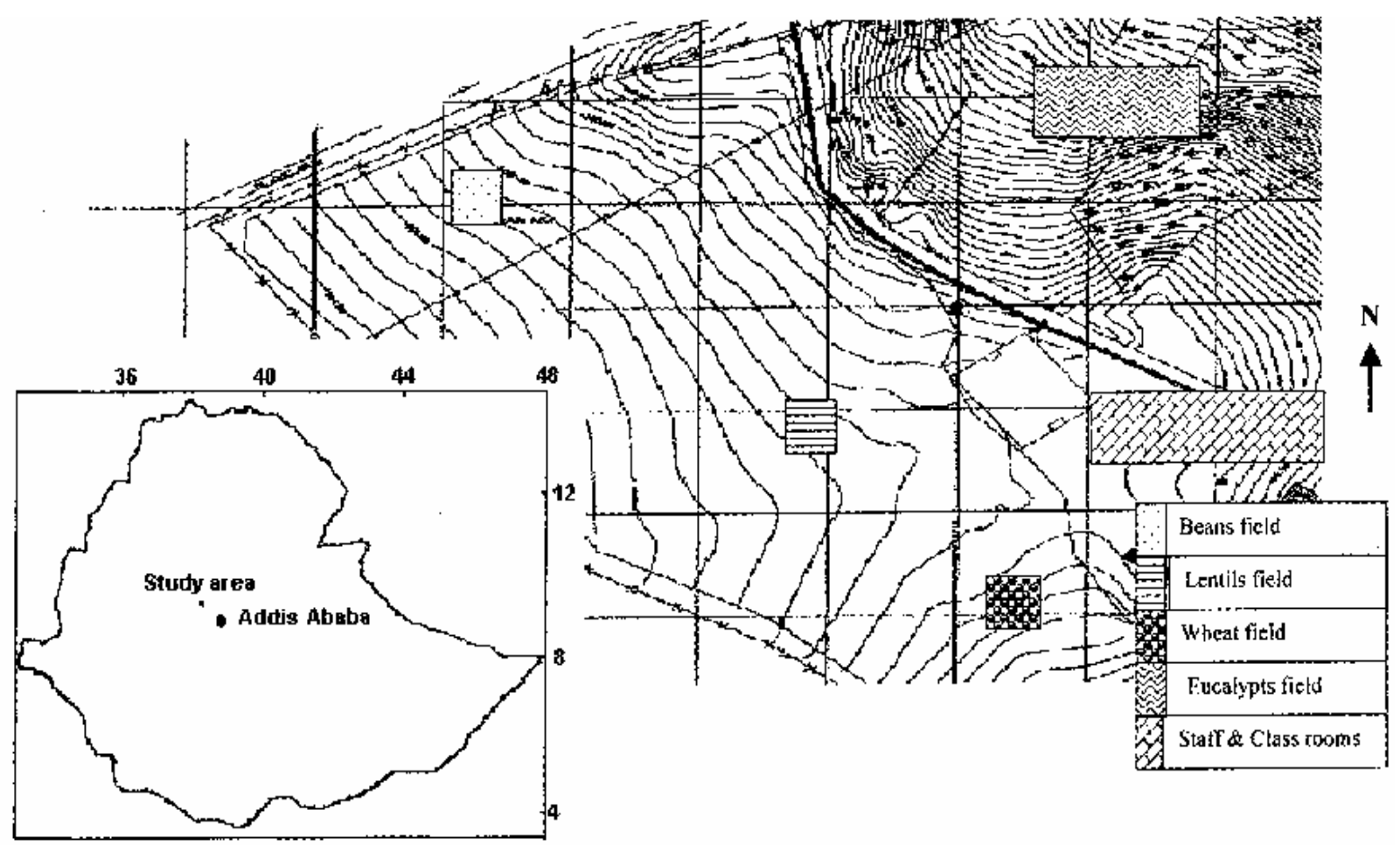

Fig. 1. Map of the study area showing spatial relationships of the grids. Ethiopia is shown in the inset. 
Trapping was initiated when the crops were in the vegetative stage and continued until the postharvest stage. Based on the differences in the longevity of these crops, trapping sessions varied. In the wheat grid, there were 10 trapping sessions from the second week of October 2002 until the first week of March 2003 (sessions 1-10). In the beans grid, there were only five trapping sessions from the second week of October 2002 till the second week of December 2002 (sessions 1-5). In the lentils grid, there were six trapping sessions from the first week of January 2003 till the second week of March 2003 (sessions 6-11). In all grids, the last two trapping sessions were post-harvest sessions.

Following the eleventh trapping session in the farm fields, 75 Sherman traps were set at different habitat types outside the farming area (under rock piles, near burrows, under eucalyptus trees, in the store and around classrooms) in the compound. This was carried out from March to April (sessions 12-14). There were 675 trap-nights outside farmlands.

Traps were kept covered with hay and weeds mainly to avoid excess heat during the day and cold during nights. Peanut butter was used as bait during all trapping operations. Traps were set in the late afternoon (15:00-16:00 h) and left in the field for three consecutive days and nights. The traps were checked twice each day during morning (06:00-08:00 h) and afternoon (16:30-18:00 h).

Species identification was accomplished using taxonomic characters (Yalden et al., 1976). This was supplemented by comparing with the specimens available in the Zoological Natural History Museum of the Addis Ababa University. Experts of the Plant Protection Department, Ministry of Agriculture were also consulted for confirmation of identity.

Handling of captured rodents followed procedures of Gurnell and Flowerdew (1990). One toe per foot was clipped to mark the individuals captured. A number was assigned to each toe. An individual mark consisted of a combination of clipped toes. No two animals on the same grid were given the same mark if they belong to the same species. Information pertaining to the species, such as the date of capture, grid type, coordinates of the trap station, identification mark and body weight (to the nearest gram, using a Pesola spring balance) were recorded. Reproduc- tive status and other striking features were also recorded before the individual was released in the site of its capture. Only the trap station and the code of the individual were recorded for recaptures within one trapping session.

Population density of rodents was estimated for each trapping session by dividing the number of rodents alive per area of the grid. Biomass was calculated using the mean weight of each species and the population estimate per hectare. Chisquare test was used to interpret the temporal and spatial variations of rodents during pre- and postharvest sessions. Spatial variation of the rodent species in different grids was also analyzed using $\chi^{2}$-test.

\section{RESULTS}

Three species of rodents, Mastomys natalensis, Mus mahomet, and Arvicanthis abyssinicus were captured from cultivated areas in the three grids. A total of 260 captures of 232 new individuals were made (Table 1). The trap success was $8.42 \%$. M. natalensis was not recorded during the first session in the wheat grid; during the first and fifth sessions in the beans grid and during the sixth and seventh sessions in the lentils grid. M. mahomet was not recorded during the first and tenth sessions in the wheat grid, during the first, third and fourth sessions in the beans grid and during the ninth session in the lentils grid. A. abyssinicus was recorded only during third to fifth and tenth sessions in the wheat grid, and during the ninth and tenth sessions in the lentils grid. It was absent in the beans grid.

M. natalensis comprised the largest percentage (68.5\%), followed by M. mahomet $(25.4 \%)$ and A. abyssinicus $(6.1 \%)$. All the three species were present in wheat and lentil grids, while only $M$. natalensis and $M$. mahomet were present in the beans grid. $M$. natalensis comprised the largest number $(65.4 \%)$ in the wheat field, followed by $M$. mahomet $(27.2 \%)$ and A. abyssinicus (7.4\%). In the beans grid, $M$. natalensis constituted $81.5 \%$ of the trapping, whereas M. mahomet formed only $18.5 \%$. In the lentils grid also, M. natalensis constituted the major proportion $(61.9 \%)$, followed by M. mahomet (28.6\%) and A. abyssinicus (9.5\%). 
Table 1. Number and biomass of rodents captured at different trapping sessions.

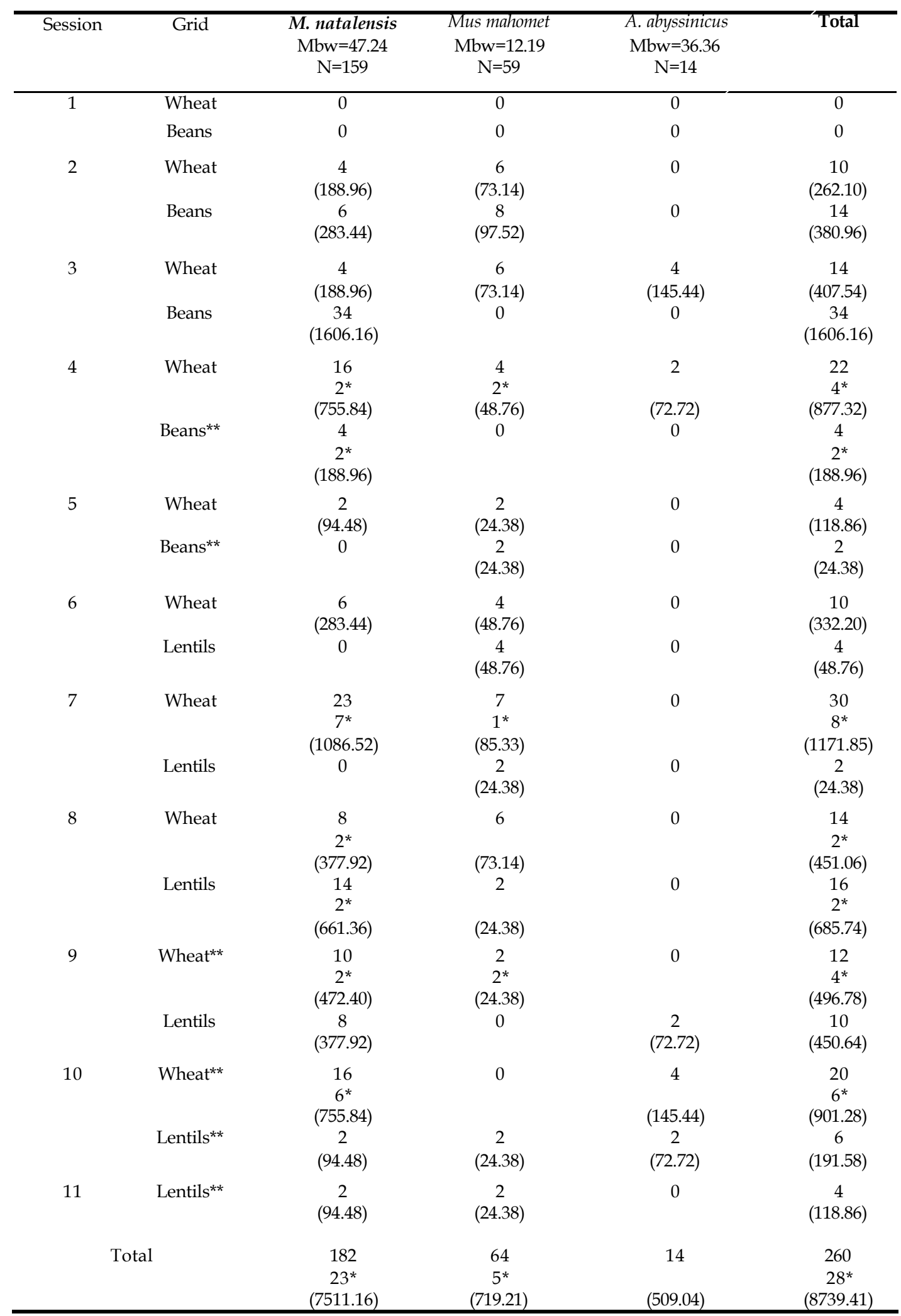

Figures in parentheses show biomass; Mbw, Mean body weight in g; N, Number of individuals captured; *, Recaptures; **, Post-harvest trapping sessions of the respective grids. 
The trap success was $10.9 \%$ in the wheat grid, $7.8 \%$ in the beans grid and $4.8 \%$ in the lentils grid. In all the grids, the maximum trap success was immediately before the harvest. The minimum trap success was during the first trapping session in the bean and wheat grids and during the second trapping session in the lentil grid. The maximum trap successes in wheat, bean and lentil grids were $20.41 \%, 23.13 \%$ and $10.88 \%$, respectively. There were only 28 recaptures during the whole trapping sessions. After harvest, the populations declined in the bean and lentil grids. In the wheat grid, a relatively high number of rodents were captured during the post-harvest sessions. Out of the total 232 individual rodents captured, $150(64.6 \%)$ were males and $82(35.4 \%)$ were females. Males outnumbered females in all the three species and in all the grids, except for M. natalensis in lentils grid (Table 2).

Table 2. Male to female ratio of the rodents trapped.

\begin{tabular}{lccc}
\hline Species & Wheat & Beans & Lentils \\
& & & \\
\hline M. natalensis & $2: 1$ & $8: 3$ & $5: 8$ \\
M. mahomet & $5: 4$ & $10: 0$ & $2: 1$ \\
A. abyssinicus & $4: 1$ & 0 & $4: 0$ \\
\hline
\end{tabular}

The population density of each of the rodent species in the three grids is given in Table 3. Density of $M$. natalensis ranged between $73 /$ ha 247/ha, whereas that of $M$. mahomet ranged between 28/ha - 104/ha and of A. abyssinicus between $0 /$ ha - 28/ha. Density of $M$. natalensis was higher in the wheat grid. Highest rodent density was recorded in the wheat grid and the lowest was in the lentils grid.

Table 3. Density of rodents (per ha) recorded in farmlands.

\begin{tabular}{lcccc}
\hline \multirow{2}{*}{ Crop } & \multicolumn{3}{c}{ Rodent species } & \multirow{2}{*}{ Total } \\
\cline { 2 - 4 } & M. natalensis & M. mahomet & A. abyssinicus & \\
\hline Wheat & 247 & 104 & 28 & 379 \\
Beans & 122 & 28 & 0 & 150 \\
Lentils & 73 & 35 & 12 & 120 \\
Total & 442 & 167 & 40 & 649 \\
\hline
\end{tabular}

Data on temporal variation in the abundance of rodents in the study grids are given in Table 4 . The abundance of all the three species of rodents in the study area was higher during pre-harvest sessions, when compared to post-harvest sessions. Substan- tial variation was observed in the abundance of rodents among the three grids. The abundance of M. natalensis and M. mahomet differed significantly $\left(\chi^{2}=39.74, \quad \mathrm{df}=2 \quad P<0.001\right.$ and $\chi^{2}=23.02, \quad \mathrm{df}=2$, $P<0.001$, respectively) among the three grids. Spatial variation of M. natalensis and M. mahomet in the wheat and bean grids was significant $\left(\chi^{2}=1523\right.$, $\mathrm{df}=1, \quad P<0.001$ and $\chi^{2}=15.51, \quad \mathrm{df}=1, \quad P<0.001$, respectively). Similarly, there was variation in the abundance of $M$. natalensis and $M$. mahomet in the wheat and lentil grids $\left(\chi^{2}=34.5, \mathrm{df}=1, P<0.001\right.$ and $\chi^{2}=12.75, \mathrm{df}=1, P<0.001$, respectively).

Table 4. A comparison of pre-harvest and postharvest capture of the three species of odents in farmlands.

\begin{tabular}{ccrc}
\hline Grid & Species & \multicolumn{2}{c}{ Pre-harvePost-harvest } \\
\hline \multirow{3}{*}{ Wheat } & M. natalensis & 15.5 & 13.0 \\
& M. mahomet & 6.5 & 1.0 \\
& A. abyssinicus & 0 & 2.0 \\
Beans & M. natalensis & 20.0 & 2.0 \\
& M. mahomet & 4.0 & 1.0 \\
& A. abyssinicus & 0 & 0 \\
\multirow{3}{*}{ Lentils } & M. natalensis & 11.0 & 2.0 \\
& M. mahomet & 1.0 & 2.0 \\
& A. abyssinicus & 1.0 & 1.0 \\
\hline
\end{tabular}

Note: Data are mean of the last two pre-harvest and the two post-harvest trapping sessions of each of the grids.

The biomass of rodents trapped in the study area is also given in Table 1. Maximum rodent biomass was revealed in the wheat grid, followed by bean and lentil grids. M. natalensis constituted for the greater proportion of biomass in all the three grids. It constituted $83.8 \%$ in the wheat grid, $94.5 \%$ in the beans grid and $80.8 \%$ in the lentils grid. The rodent biomass varied between grids and between trapping sessions. In the wheat grid, the maximum biomass recorded per hectare was $1172 \mathrm{~g}$ during the seventh session and the minimum was $262 \mathrm{~g}$ during the second session. In the beans grid, the maximum was $1606 \mathrm{~g}$ during the third session and the minimum was $24 \mathrm{~g}$ during the fifth session. In the lentils grid, the maximum biomass was $686 \mathrm{~g}$ during the eighth sessions and the minimum was $24 \mathrm{~g}$ during the seventh session.

There were 61 captures of 56 individual rodents outside the cultivated areas. A. abyssinicus comprised the largest number (22), followed by $M$. natalensis (21) and M. mahomet (13). 


\section{DISCUSSION}

Investigations on rodent pests in the tropical farm fields are of utmost importance as the crop loss due to rodents is as high as $26 \%$ as reported for the maize fields in Ethiopia (Afework Bekele et al., 2003). All the three species of rodents recorded during the present investigation have wide distributions across many parts of Ethiopia. Among them, Arvicanthis spp. and Mastomys spp. are known as major agricultural pests (Afework Bekele and Leirs, 1997; Afework Bekele et al., 2003). In the present study area, M. natalensis was the most common rodent. Even though Arvicanthis is also known as a major pest in farmlands, this genus might prefer natural habitats for shelter (Delany and Roberts, 1978; Afework Bekele and Leirs, 1997), and visit nearby farmlands for food. The absence of Arvicanthis in the beans field during the present investigation might be due to the fact that this field was more than $300-400 \mathrm{~m}$ away from their sites of shelter. Further, the nearby wheat field might provide enough food for them.

The trap success in the wheat grid was higher than in bean and lentil grids. Trap success also varied during different sessions of the study period. The highest trap success was obtained in sessions immediately before harvest. This shows that rodents favour an area when crops are in maturing stage as it provides abundant food. The decline in trap success after harvest in the bean and lentil grids relates to the environmental instability of these farmlands. As maturing crops are excellent sources of food, rodents breed at their maximum potential during this phase of the farm cycle. Harvest results in a shortage of food; then rodents leave the area in search of food. Earlier studies in two Kenyan highlands also revealed similar results, especially with regard to $M$. natalensis (Taylor and Green, 1976). The proximity to natural habitats, rocky areas and crevices, which provide shelter, and the availability of seeds left on the ground after harvest might contribute for the relatively high trap success in the wheat grid even after harvest. The trap success of $8.42 \%$ during the present investigation compares more or less with the mean trap success of $9.1 \%$ reported by
Afework Bekele (1996) for rodents in Menagesha State Forest, Ethiopia.

Leirs (1995) reviewed the population density of different Mastomys species in Africa and revealed up to one thousand animals per hectare in outbreak years and several hundreds per hectare during seasonal peaks. In the present study, rodent density in the farmland ranged between 6-94/ha for M. natalensis, which is a low density. Temporal variation in the abundance of rodents occurred during three out of the 10 sessions in the wheat grid. During most of the sessions, only $M$. natalensis and $M$. mahomet were recorded in the wheat grid. Moreover, the relative abundance of M. matalensis and M. mahomet varied significantly between pre- and post-harvest sessions. Jacob and Brown (2000) have emphasized that harvesting not only results in food scarcity, but also exposes rodents to predators, leading to increased predation risk. Naturally, they move away from such areas to more suitable areas, resulting in decreased population density in farmlands after harvest. As there were predators such as cats in the present study area, the rodent population in this area might also have predatory effect.

Rodents are not uniformly distributed in all habitat types. Afework Bekele (1996) has revealed the distribution patterns of 10 species of rodents across different vegetation zones including human habitats in Menagesha forest area. The present findings show that $M$. natalensis is the most widely distributed species in the study area. M. mahomet is common in wheat and lentil fields, whereas $A$. abyssinicus was more abundant outside farmlands. Bekele Tsegaye (1999) has already reported that $A$. abyssinicus does not prefer farmlands. The variation in the biomass recorded in different trapping sessions was associated with the fluctuation in population size in the grids. During most of the sessions, there were more rodents in the wheat grid than in other grids. Correspondingly, rodent biomass was also more in the wheat grid.

It is to be emphasized that rodent control programmes would be more effective if applied during the pre-breeding season, which also coincides with the reproductive phase of the vegetation communities around (Workneh 
Gebresilassie et al., 2004). Further, as rodents get shelter in areas of natural vegetation around farmlands throughout the seasons, it is advised to follow clean farming practices by clearing shrubs and rock piles in areas around farmlands, as an environmental means of rodent control.

\section{ACKNOWLEDGEMENTS}

We are grateful to the Addis Ababa University for financial assistance and facilities received for this esearch work. We are also thankful to the three anonymous referees for their valuable suggestions for improvement of this paper.

\section{REFERENCES}

1. Afework Bekele, Capanna, E., Corti, M., Marcus, L.F. and Schlitter, D.A. (1993). Systematics and geographic variation of Ethiopian Arvicanthis. J. Zool., Lond. 230:117-134.

2. Afework Bekele (1996). Rodents of the Menagesha State Forest, Ethiopia, with an emphjasis on the endemic Praomys albipes Rüppell 1842. Trop. Zool. 9:201-212.

3. Afework Bekele and Leirs, H. (1997). Population ecology of rodents of maize fields and grassland in central Ethiopia. Belg. J. Zool. 127:39-48.

4. Afework Bekele, Leirs, H. and Verhagen, R. (2003). Composition of rodents and damage estimates on maize farms at Ziway, Ethiopia. In: Rats, Mice and People: Rodent Biology and Management, pp. 262-263, (Singleton, G.R., Hinds, L.A., Krebs, C.J. and Spratt, D.M. eds). Australian Center for International Agricultural Research, Canberra.

5. Bekele Tsegaye (1999). Species Composition, Distribution and Population Dynamics of Rodents of Entoto National Park. M. Sc. Thesis, Addis Ababa University, Addis Ababa.

6. Delany, M.J. and Roberts, J.C. (1978). Seasonal population changes in rodents in the Kenya Rift Valley. Bull. Carnegie Mus. Natural Hist. 6:97-108.

7. Douganboupha, B., Aplin, K. P. and Singleton, G. R. (2003). Rodent outbreaks in the uplands of Laos: analysis of historical patterns and the identity of nuu khii. In: Rats, Mice and People: Rodent Biology and Management, pp. 103-110, (Singleton, G.R., Hinds, L.A., Krebs, C.J. and Spratt, D.M. eds). Australian Center for International Agricultural Research, Canberra.
8. FAO (2002). FAO statistics http://www.faoorg/ Waicent/ faoinfo/ economic/ess/index.html

9. Fiedler, L.A. (1994). Rodent Pest Management in East Africa. Plant Production and Protection Paper No. 123, Food and Agriculture Organization (FAO), Rome.

10. Gurnell, J. and Flowerdew, J.R. (1990). Live Trapping Small Mammals: A Practical Guide. The Mammal Society, London.

11. Jacob, J. and Brown, J.S. (2000). Microhabitat use, giving up densi ties and temporal activity as short and long term anti-predator behaviours in common voles. Oikos, 90:131-138.

12. Leirs, H. (1995). Population Ecology of Mastomys natalensis (Smith, 1834): Implications for Rodent Control in Africa. Belgian Administration for Development Cooperation, Brussels.

13. Leirs, H. (2003). Management of rodents in crops. In: Rats, Mice and People: Rodent Biology and Management, pp. 183-189, (Singleton, G.R., Hinds, L.A., Krebs, C.J. and Spratt, D.M. eds). Australian Center for International Agricultural Rsearch, Canberra.

14 Leirs, H., Verhagen, R. and Verheyen, W. (1994). The basis of reproductive seasonality in Mastomys rats (Rodentia: Muridae) in Tanzania. J.Trop.Ecol. 10: 55-66.

15. Makundi, R.H., Oguge, N.O. and Mwanjabe, P.S. (1999). Rodent pests. Belg. J. Zool. 128: 167-175.

16. Pech, R.P., Hood, G.M., Singleton, G.R., Salmon, E., Forrester, R.I. and Brown, P. R. (1999). Models for predicting plagues of house mice (Mus domesticus) in Australia. In: Ecologically Based Management of Rodent Pests, pp. 81-112, (Singleton, G.R., Hinds, L.A., Leirs, H. and Zhang, Z. eds). ACIAR Monograph No. 59. Australian Center for International Agricultural Research, Canberra.

17. Peltz, H.J. (1989). Ecological aspects of damage to sugar beet seeds by Apodemus sylvaticus. In: Mammals as Pests, pp. 34-48 (Putman, R.J. ed). Chapman and Hall, London.

18. Taylor, K. D. and Green, M. G. (1976). The influence of rainfall on diet and reproduction in four African rodent species. J. Zool., Lond. 180:367-389.

19. Tristiani, H. and Murakami, O. (1998). Reproduction and survival of the rice field rat Rattus argentiventer on rice plant diet. Bel. J. Zool. 128: 167175.

20. Williams, J.M. (1985). Interrelationship and impact on agriculture of Rattus species in the tropical South Pacific. Acta Zool. Finnica 173: 129-134. 
21. Wilson, D.E. and Reeder, D.M. (1993). Mammal Species of the World. Smithsonian Institution Press, Washington, D.C.

22. Workneh Gebresilassie, Afework Bekele, Gurja Belay and Balakrishnan, M. (2004). Microhabitat choice and diet of rodents in Maynugus irriga- tion field, northern Ethiopia. Afr. J. Ecol. 42: 315-321.

23. Yalden, D. W., Largen, M. J. and Kock, D (1976). Catalogue of the mammals of Ethiopia. Insectivora and Rodentia. Mon. Zool. Ital. (N. S.) (Suppl.) 8: 1-118. 